Endocrinol. Japon., Vol. 3, No. 3 (1956).

\title{
EFFEGT OF HYPOPHYSECTOMY UPON MITOTIC PROLIFERATION IN REGENERATING TISSUES OF THE AIUULT NEWT
}

\author{
SAKAE INOUE \\ Section of Biological Research, Endocrinological Laboratories, \\ School of Medicine, Gunma University, Maebashi
}

Experiments performed by Schotté (1926), Schotté and Hall (1951, 1952), etc., showed evidently that regeneration in the adult newt is under the significant control by certain of the pituitary hormones. In connection with the study of mitotic proliferation in regenerating tissues, the present author attempted to observe the phases of mitotic activity in regenerating tissues as influenced by hypophysectomy, and effects were pursued by injection of several hormones. This report concerns the mitotic activity in regenerating epidermis and mesodermal tissues of the limb and dorsal skin in hypophysectomized adult newt.

\section{MATERIAL AND METHOD}

The present experiments were carried out during March and April with the use of the adults of the common newt, Triturus pyrrhogaster. Hypophysectomy was performed by means of buccal approach, the parasphenoid bone being perforated with the aid of trephine of $1.5 \sim 2.0$ $\mathrm{mm}$ in diameter. Forelimbs were bilaterally amputated at the midst of the stylopodium, and the remaing humeral bones were extirpated. A wound was made by excising a piece of skin of about $1.5 \mathrm{~mm}$ square from the dorsal side of the operated animals. After such successive operations animals were placed for three or four days in the finger-bowls in moist condition, then transferred to culture water at room temperature. With these animals hypophysectomy was performed at the end of four days following the preceding operations. Blanching took place in some measure, which was indicative of successful hypophysectomy. Operated animals were fixed with Bouin's fluid on the 2nd, 4th, 7th, 10th, 14th, 19th, 24th and 29th days beginning from the day of excision of the forelimbs and dorsal skin. Two or three samples were chosen from the fixed materials, which were cut in $7 \mu$ thickness after the routine paraffin technique and stained with Delafield's hematoxylin and eosin or after Mallory's triple staining method. Rate of mitosis was counted by the following method at randomly selected microscopic fields at the magnification of $\times 600$. With the sections chosen at 3 or 4 intervals in order to avoid duplicated counting of the same cells, numbers of the resting cells and of the mitotic cells showing distinct features of the prophase, metaphase, and anaphase were counted altogether. In the present study, counting was made on regenerating epidermis, old epidermis surrounding the operational wound in about $2 \mathrm{~mm}$ range from the periphery of the latter and cells in inner tissues of limb including. blastem elements with the exception of hematogenetic cells and nerve sheath cells. The conventional $\chi^{2}$ test was adopted for the determination of the significance of differences enumerated.

Received for publication September 3, 1956. 


\section{RESULTS}

\section{Some histologic and gross observations}

During a few days following hypophysectomy, any sign of inner histological difference between the normal and the hypophysectomized limbs was not observable. Apparent indications of the process of dedifferentiation were seen in the sample fixed 14 days after amputation (10 days after hypophysectomy). Fraying out of the cut end of the nerve sheath, tendency of separation of the sheath cells and liberation of the muscle cells from the isolated muscle tissues were commonly observed, all of which were pointed out by Thornton (1938) as characteristic histological features of dedifferentiation in the course of regeneration of exarticulated limbs in larval Amblystoma. Sign of retardation of regenerating process could be seen within this period; namely, the quantity of blastematous elements that were tending to aggregate below the newly formed epidermis was comparatively less in hypophysectomized limbs than in normally regenerating limbs. Evident features of histological differences in the inner part of the limbs between normal and hypophysectomized individuals could be seen in the limbs fixed 19 days after amputation (15 days after hypophysectomy). Normally regenerating limbs in animals fixed 19
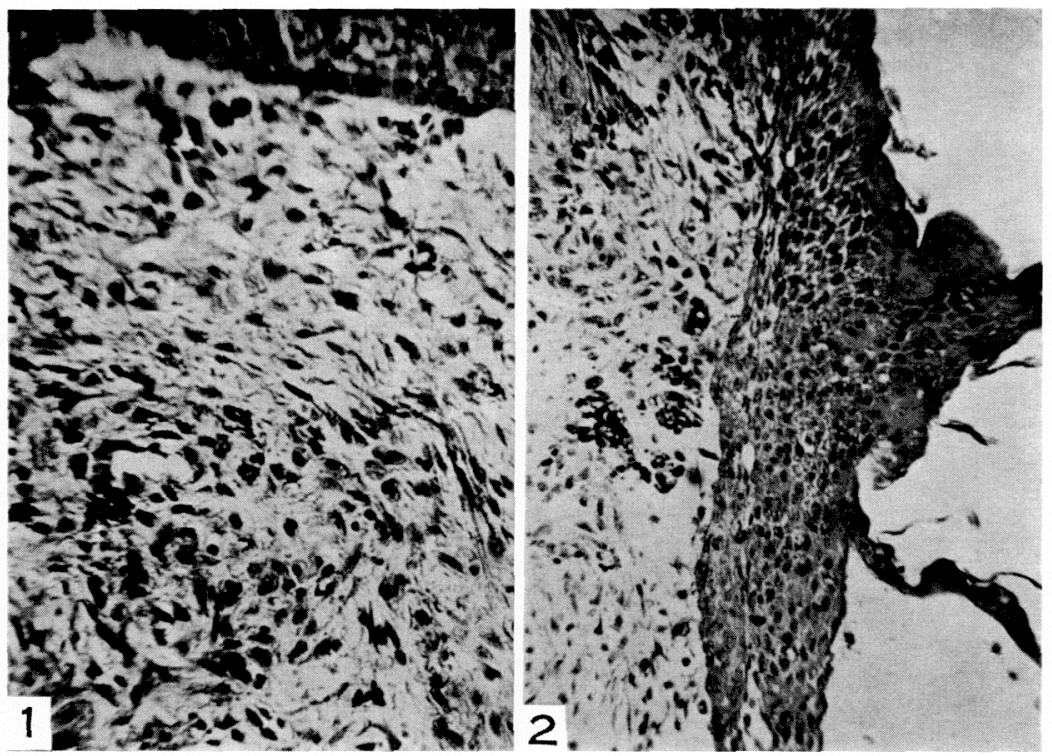

Figs. 1-2. Photomicrographs showing occurrence of the blastem cells underneath regenerating epidermis of the normal (Fig. 1) and the hypophysectomized (Fig. 2) cases as observed 19 days after amputation (15 days after hypophysectomy). Blastem cells are forming aggregation beneath the epidermis in the normal case, though small quantity of blastem cells are seen in the area surrounded by contracted epidermis together with the cut-stump of the inner tissues in the hypophysectomized case. Note sprouting, cornification and desquamation in the epidermis of the hypophysectomized case. Magnifications: Fig. 1: $\times 200$, Fig. 2: $\times 100$ 
days after amputation showed occurrence of considerable amount of the blastem cells, being aggregated underneath the epidermis, while such was not the case with the limbs in hypophysectomized animals (Figs. 1 and 2). Blanching of the body was observed by unaided eyes with animals subjected to hypophysectomy, which became more or less pronounced in one or two days after the operation. As a matter of fact, transparent preparations of the intact skin taken out 16 hrs. after hypophysectomy showed marked pigment concentration of the dermal as well as the epidermal melanophores. And disintegration of contracted melanophores was frequently observed, fragments of melanin debris being scattered among the connective tissue of the dermis. Another conspicuous change occurred in the skin was learned to be a marked contraction of regenerated epidermis being associated with formation of irregular outward epithelial sprouting, severe cornification and desquamation (Fig. 2). Such a change became discernible by gross observations in about

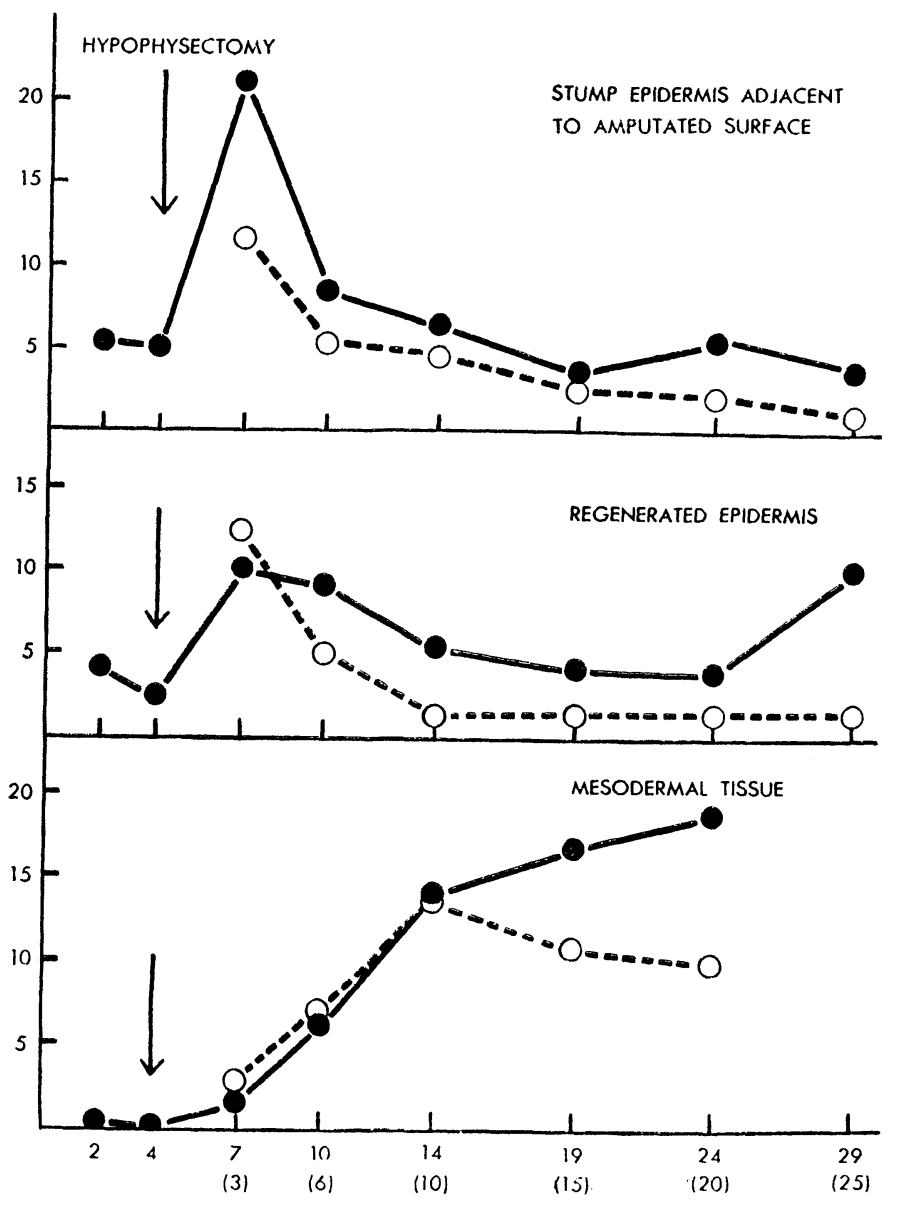

Fig. 3. Mitotic rate in forelimb regeneration of the normal (solid lines) and the Hypophysectomized (dotted lines) cases. Hypophysectomy was performed 4 days after amputation of the limbs. 
two weeks after hypophysectomy.

2. Milotic activity in regenerating tissues

a. Mitolic activity in normal regeneration of forelimb In this study, two phases of mitotic activity could be discriminated in regenerating process of the forelimb, being illustrated by Fig. 3 . The one took place in the epidermis in early stage of regeneration, and the other in the mesodermal tissues subsequent to the epidermal mitotic activity. The mitotic activity in both regenerating and stump epidermis increased continuously, attaining a maximum at the end of 7 days and gradually declining thereafter. The activity of the regenerating epidermis in 29-day specimens increased again in spite of low mitotic level in the stump epidermis. Parallelism was observed between such a phenomenon and the development of the blastema.

The process of mitotic activity in mesodermal tissues was much different from that in the epidermis, and no significant increase of the mitosis-rate was observed in the former during the wound-healing period. Slight increase of mitotic activity was discernible on the 7 th day after amputation. 10-day specimens showed higher activity. Then it continued to increase gradually during successive 24 days. It can be stated on the basis of observations that the increase of mitotic activity in the epidermis was not synchronized with that in the mesodermal tissues.

b. Mitotic activity in regenerating process of forelimb after hypophysectomy In the experiments in which hypophysectomy was carried out 4 days after amputation of the limbs, the process of mitotic activity was observed being parallel at lower levels with that in the non-hypophysectomized animals (dotted lines in Fig. 3.) The peak of epidermal mitosis-rate was attained in 7-day specimens too. Thereafter, it progressed in parallel with the normal activity up to 24 days after cutting, after which period no significant increase was observable in spite of the increase of mitotic

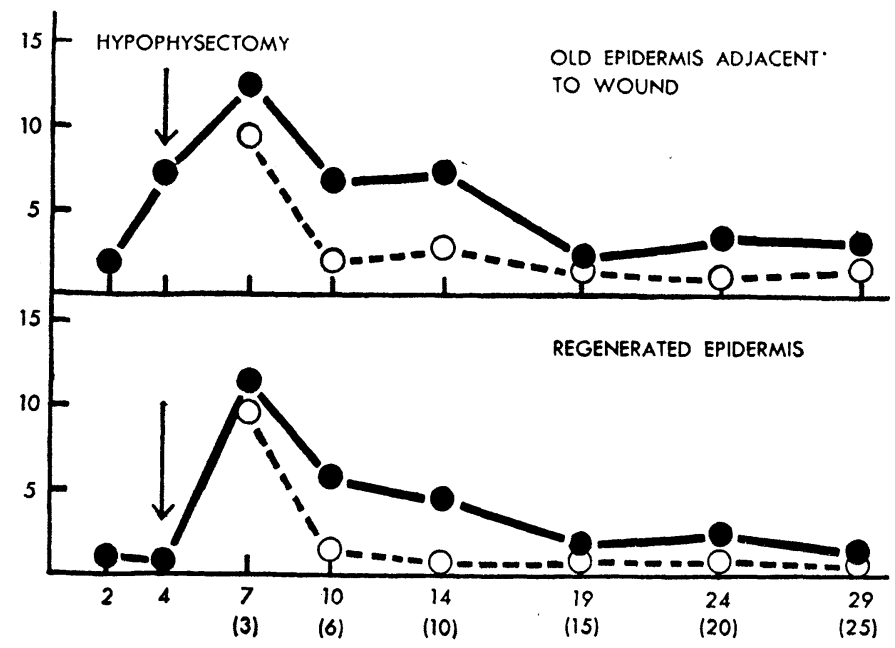

Fig. 4. Mitotic rate in the healing dorsal skin in the normal (solid line) and the hypophysectomized (dotted line) cases. Hypophysectomy was performed 4 days after operative impairment of the integument. 
activity in the normal regenerating epidermis.

In the mesodermal tissues, mitotic increase was observed in 7 days after limbamputation (3 days after hypophysectomy). Then the mitotic activity progressed in parallel with the normal cases at lower levels, until the stage of blastem-cell formation was reached at. In the period of the latter stage, cell proliferation was significantly inhibited in the mesodermal components. Such a phenomenon was correlated with feeble formation of the blastem cells in the limbs of the hypophysectomized animals, as mentioned already.

Table 1 shows that the number of mitoses in the hypophysectomized rcgenerates is significantly lower as compared with the corresponding datum in normal regenerates. But in this experiment, the general tendency of increase of mitntic activity in the regenerating epidermis looked like unimpaired, for even the suppressed mitosis-rate in the hypophysectomized regenerate was found predominating the rate in the normal control.

c. Mitotic activity in wound-healing in dorsal skin The process of mitotic activity in the healing dorsal skin of normal individuals progressed in similar way as in the epidermis of the regenerating limbs. That is, a maximum of the rate was detected on the 7th day, then the activity declined gradually (Fig. 4). In the wound-healing of dorsal skin, no formation of the blastema was associated, so elevation of the mitosis-rate in the subsequent period, which was seen in the forelimb regeneration, was not observable. The mitosis-rate in the hypophysectomized animals also progressed in similar way as in the normal cases, but the degree of activity was significantly lower in comparision with that of normal cases (Table 1).

On the whole, it might be concluded from these observations that the mitotic activity occurring in the regenerating tissues of the adult newt was considerably suppressed after hypophysectomy.

Table 1. Number of Mitoses in Materials of the Normal and the Hypophysectomized Cases

\begin{tabular}{|c|c|c|c|c|c|c|c|}
\hline \multirow[b]{2}{*}{ Portions observed } & \multicolumn{3}{|c|}{ Normal cases } & \multicolumn{3}{|c|}{ Hypophysectomized cases } & \multirow[b]{2}{*}{$P$} \\
\hline & $\begin{array}{c}\text { Number of } \\
\text { cells } \\
\text { observed }\end{array}$ & $\begin{array}{l}\text { Number of } \\
\text { celis in } \\
\text { mitosis }\end{array}$ & $\begin{array}{l}\text { Percent- } \\
\text { age of } \\
\text { mitosis }\end{array}$ & $\begin{array}{c}\text { Number of } \\
\text { cells } \\
\text { observed }\end{array}$ & $\begin{array}{l}\text { Number of } \\
\text { cells in } \\
\text { mitosis }\end{array}$ & $\begin{array}{l}\text { Percent- } \\
\text { age of } \\
\text { mitosis }\end{array}$ & \\
\hline \multicolumn{8}{|l|}{ Regenerating forelimb } \\
\hline Stump epidermis & 41132 & 336 & 0.82 & 39459 & 182 & 0.46 & $<0.01$ \\
\hline Regenerating epidermis & nis 39993 & 288 & 0.72 & 39789 & 152 & 0.38 & II \\
\hline Mesodermal tissue & 45808 & 577 & 1.26 & 44233 & 432 & 0.98 & "I \\
\hline \multicolumn{8}{|l|}{ Healing dorsal skin } \\
\hline Old epidermis & 38737 & 222 & 0.57 & 39148 & 124 & 0.32 & $" 1$ \\
\hline Regenerating epidermis & his 37639 & 169 & 0.45 & 38785 & 91 & 0.23 & $" 1$ \\
\hline Hindlimb epidermis & 38546 & 53 & 0.14 & 38754 & 54 & 0.14 & $>0.9$ \\
\hline
\end{tabular}

Hypophysectomy was performed 4 days after amputation of the limbs and partial removal of the dorsal skin.

\section{COMMENTS}

In the present series of experiments, the effect of hypophysectomy upon the mitotic activity occurring in regenerating processes in the adult newt was chiefly examined. Increase of the mitotic activity in regenerating tissues of amphibians 
has becn repeatedly demonstrated by a number of workers. In preccding experiments, the present author confirmed the generalized observation that mitotic increase takes place in the period following $2 \sim 4$ days of the latent period in the regenerating epidermis of the adult newt (Inoue, 1954). In the present experiments, two different phases of mitotic activity could be detected in the regenerating epıdermal and mesodermal tissues. In the epidermis, peak of the mitotic activity was attained within one or two weeks after limb-amputation, while there observed no sign of comparable activity in the mesodermal tissues. In early stages of regeneration, the inner tissues of the limb were in the process of demolition and dedifferentiation, which is admitted to be important for the initiation of regeneration (Needham, 1952), no increase of mitotic activity being detected among the cells of mesodermal origin. Signs of mitotic increase could be detected when blastem elements began to appear, and gradual increase of the mitotic activity in this part was parallel with the development of the blastema. In conclusion, two phases of mitotic activity seemed to take place in the regenerating process of the limb-tissues, the one appearing early in the epidermis and the other in the mesodrmal components in the later period. This confirmes the observation of Manner (1954).

As the result of observations of the mitotic activity in the regenerating limb as well as in the healing dorsal skin in hypophysectomized newts, it appears to be established that the mitotic activity in these regenerating tissues is significantly suppressed in the absence of the pituitary. That is to say, the epidermis of hypophysectomized cases shows lower mitotic rate than that in the normally regenerating limb. In the mesodermal tissues, tendency of mitotic activity which is correlated with inhibition of the blastema development can be detected at significantly lower level than in the normal cases.

In parallel with the inhibition of mesodermal mitotic activity, small quantity of blastematous elements originates in the early phase in hypophysectomized individuals, which is indicative to be the most remarkable sign of suppression of regeneration. The results show that the disintegration and the dedifferentiation phases are affected in considerably measure in the absence of the pituitary, which is in agreement with the view of Schotte and Hall (1952) that the limbs initiating regeneration for as much as 10 days prior to hypophysectomy are wholly affected after removal of the pituitary.

What is the cause of suppression of the mitotic proliferation in regenerating tissues cannot be stated exactly at present, since hormonic unbalance caused by hypophysectomy seems to be extraordinarily complex. Neverthless, it is suggestive that the mitotic proliferation in the regenerating limbs of non-hypophysectomized adult newts is temporarily inhibited by injection of cortisone (Manner, 1955), and further it is postulated that mitosis in some sea-urchin eggs is inhibited by cortisone (Menkin and Pepper, 1954).

\section{SUMMARY}

Phases of mitotic activity and some of the histologic features in the regenerating tissues of the forelimb and of the dorsal skin were observed for 29 days after 
partial destruction of the organs in question in both normal and hypophysectomized adult newts. Two consecutive phases of mitotic activity were learned to take place in regenerating process of the limb-tissues. The one progresses in the epidermis in the early period of regeneration, and the other in the mesodermal tissues in the period succeeding the days of epidermal proliferation. Hypophysectomy was found to inhibit both of the mitotic activities in the regenerating limbs and the epidermal activity in the healing dorsal skin significantly.

\section{REFERENCES}

Hall, A. B. and O. E. Schotté (1951). J. Exp. Zool. 118, 363.

Inoue, S. (1954). Sci. Rep Tohoku Univ. Biol. 20, 182.

Manner, H. W. (1953). J. Exp. Zool. 122, 229.

Manner, H. W. (1955). Growth 14, 169.

Menkin, V. and M. Pepper (1954). Biol. Bull. 107, 316.

Needham, A. E. (1952). Regeneration and Wound-Healing. John Wilcy and Sons Inc., N.Y.G. $152 \mathrm{pp}$.

Schotté, O. E. (1926). Soc. Biol. 94, 1177.

Schotté, O. E. and A. B. Hall (1952). J. Exp. Zool. 121, 521

Thornton, C. S. (1938). J. Morph. 62, 219. 